\title{
Prevalence and management of driveline infections in mechanical circulatory support - a single center analysis
}

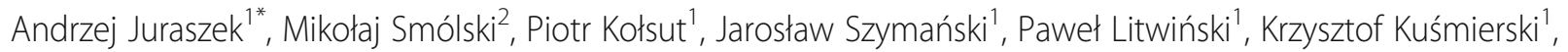
Joanna Zakrzewska-Koperska ${ }^{3}$, Maciej Sterliński ${ }^{3}$, Tomasz Dziodzio ${ }^{4 *}$ and Mariusz Kuśmierczyk ${ }^{1 \dagger}$

\begin{abstract}
Background: Driveline infections in continuous-flow left ventricular assist devices (cf-LVAD) remain the most common adverse event. This single-center retrospective study investigated the risk factors, prevalence and management of driveline infections.

Methods: Patients treated after cf-LVAD implantation from December 2014 to January 2020 were enrolled. Baseline data were collected and potential risk factors were elaborated. The multi-modal treatment was based on antibiotic therapy, daily wound care, surgical driveline reposition, and heart transplantation. Time of infection development, freedom of reinfection, freedom of heart transplantation, and death in the follow-up time were investigated.

Results: Of 75 observed patients, 26 (34.7\%) developed a driveline infection. The mean time from implantation to infection diagnosis was 463 ( \pm 399 ; range, $35-1400)$ days. The most common pathogen was Staphylococcus aureus $(n=15,60 \%)$. First-line therapy was based on antibiotics, with a primary success rate of $27 \%$. The majority of patients $(n=19 ; 73.1 \%)$ were treated with surgical reposition after initial antibiotic therapy. During the follow-up time of 569 ( \pm 506 ; range $32-2093$ ) days, the reinfection freedom after surgical transposition was $57.9 \%$. Heart transplantation was performed in eight patients due to resistant infection. The overall mortality for driveline infection was $11.5 \%$.

Conclusions: Driveline infections are frequent in patients with implanted cf-LVAD, and treatment does not efficiently avoid reinfection, leading to moderate mortality rates. Only about a quarter of the infected patients were cured with antibiotics alone. Surgical driveline reposition is a reasonable treatment option and does not preclude subsequent heart transplantation due to limited reinfection freedom.
\end{abstract}

Keywords: Driveline infection, Left ventricular assist device, Surgical reposition

\footnotetext{
* Correspondence: anderso@o2.pl; tomasz.dziodzio@charite.de

†Tomasz Dziodzio and Mariusz Kuśmierczyk contributed equally to this work.

'Department of Cardiac Surgery and Transplantation, The Cardinal Stefan

Wyszyński National Institute of Cardiology, ul. Alpejska 42, 04-628 Warsaw,

Poland

${ }^{4}$ Department of Surgery, Campus Charité Mitte and Campus

Virchow-Klinikum Charité -Universitätsmedizin Berlin, corporate member of

Freie Universität Berlin, Humboldt-Universität zu Berlin, and Berlin Institute of

Health, Augustenburger Platz 1, 13353 Berlin, Germany

Full list of author information is available at the end of the article
}

\section{$\triangle B M C$}

C C The Author(s). 2021 Open Access This article is licensed under a Creative Commons Attribution 4.0 International License, which permits use, sharing, adaptation, distribution and reproduction in any medium or format, as long as you give appropriate credit to the original author(s) and the source, provide a link to the Creative Commons licence, and indicate if changes were made. The images or other third party material in this article are included in the article's Creative Commons licence, unless indicated otherwise in a credit line to the material. If material is not included in the article's Creative Commons licence and your intended use is not permitted by statutory regulation or exceeds the permitted use, you will need to obtain permission directly from the copyright holder. To view a copy of this licence, visit http://creativecommons.org/licenses/by/4.0/ The Creative Commons Public Domain Dedication waiver (http://creativecommons.org/publicdomain/zero/1.0/) applies to the data made available in this article, unless otherwise stated in a credit line to the data. 


\section{Background}

The success of continuous-flow left ventricular assist device (cf-LVAD) therapy is reduced by several severe complications like hemorrhagic and thromboembolic events, arrhythmias, multi-organ failure, and driveline infections [1-4]. Driveline infections are the most common adverse event, occurring in about $28 \%$ of all patients with an implanted cf-LVAD $[4,5]$. It is suspected that the transcutaneous pathway of the driveline and the chronic traumatic conditions are the triggers for infections [3]. A negative impact on the necessity of reoperation, ascending strokes, postponing transplantation, and survival is described in literature $[3,6]$. Conservative management is based on the use of antibiotic therapy, and the surgical approach includes the use of vacuum dressings and driveline reposition. If all other strategies fail, heart transplantation is applied as last treatment resort $[6,7]$. Currently, data regarding the treatment strategies and outcome of complications related to driveline infections is limited [6-12].

\section{Aim of the study}

This retrospective single-site study investigated the risk factors of driveline infections and the results of their medical and surgical treatments in cf-LVAD patients.

\section{Methods}

\section{Patients and data}

All patients treated after cf-LVADs implantation from December 2014 to January 2020 in our center were enrolled. The study was approved by ethics committee. Patients provided written informed consent to participate in the study. The following cf-LVADs were implanted as bridge to transplantation therapy: HeartWare (Medtronic, Minneapolis, MN, USA), Heartmate II and HeartMate III (both Abbott, Abbott Park, IL, USA). Baseline data included patients' age and gender, implantation indication, and device type. Specific data included time from cf-LVAD implantation to driveline infection, pathogen type, antibiotic treatment strategy, and time from diagnosis to surgical reposition. The freedom of reinfection in the follow-up time was investigated.

Risk factors for the development of driveline infections were assessed individually, including: obesity, defined as body mass index (BMI) > $30 \mathrm{~kg} / \mathrm{m}^{2}$; diabetes mellitus; age $<45$ years; intensive care unit (ICU) stay over 2 weeks; history of previous mechanical circulatory support (MCS), defined as any type of left ventricle support implanted before the infection-associated cf-LVAD device, including short-term left ventricle support; chronic kidney disease, defined as abnormally elevated serum creatinine for more than 3 months or calculated glomerular filtration rate $($ GFR $)<60 \mathrm{~mL} / \mathrm{min} / 1.73 \mathrm{~m}^{2}$. Finally, the number of heart transplantations due to driveline infections and overall mortality were recorded.

\section{Regular driveline exit care in non-infected patients} Changing the dressing every 2-3 days and always after exposure to water was recommended. In case of efflux on the driveline exit site, daily dressing was necessary.

For the dressing change procedure disposable sterile gloves were used. Three separate sterile packets of gauze pads were placed on a clean surface. One part was soaked in a disinfectant that can be used on open wounds (Octanisept ${ }^{\oplus}$, Schülke \& Mayr GmbH, Norderstedt, Germany), the second part was soaked in a disinfectant liquid containing the active substances: 2propanol, 1-propanol, 2-diphenylol (Kodan ${ }^{\oplus}$, Schülke \& Mayr GmbH, Norderstedt, Germany), leaving the third part dry. The soaked Kodan gauze was put on the driveline exit point and left there for at least two minutes. After the specified time, the gauze pad was removed from the driveline exit point and the driveline exit place was cleaned with Octanisept ${ }^{\oplus}$, using movements in direction from the wound outwards. The area around the wound was dried while avoiding the cable exit area. As a standard practice, we used an antiseptic and antimicrobial dressing impregnated with polyhexamethylene biguanide. It was a dressing with an additional cutout to cover the cable exit point. Finally, covering of the central part with a transparent and breathable foil dressing was required, to separate the wound from the environment. In order to protect the driveline against enhanced movement, additional fixing elements were added.

\section{Treatment strategy}

The treatment strategy comprised of three stages: antibiotic therapy, surgical driveline reposition, and heart transplantation. Antibiotics were used as first-line therapy. The first choice antibiotic agent was empiric and then adjusted to the culture results. Additionally, daily wound care comprising of local antiseptic application and dressing replacement was performed in each stage.

The surgical approach was chosen in resistant infections. The surgery was performed under general anesthesia. The skin was cut above the run of the driveline, and the velvet cover was removed from the driveline. Depending on the proximity of infection, the former driveline site was treated with a vacuum dressing or sutured secondarily. Primary wound closure was performed in proximal infections. In the case of vacuum therapy, the wound was sutured secondly. Similarly, depending on the degree of the infection, a new incision was made on the contralateral side of the abdomen, creating a new driveline site either in the first or second surgery. The skin over the new driveline placement was 


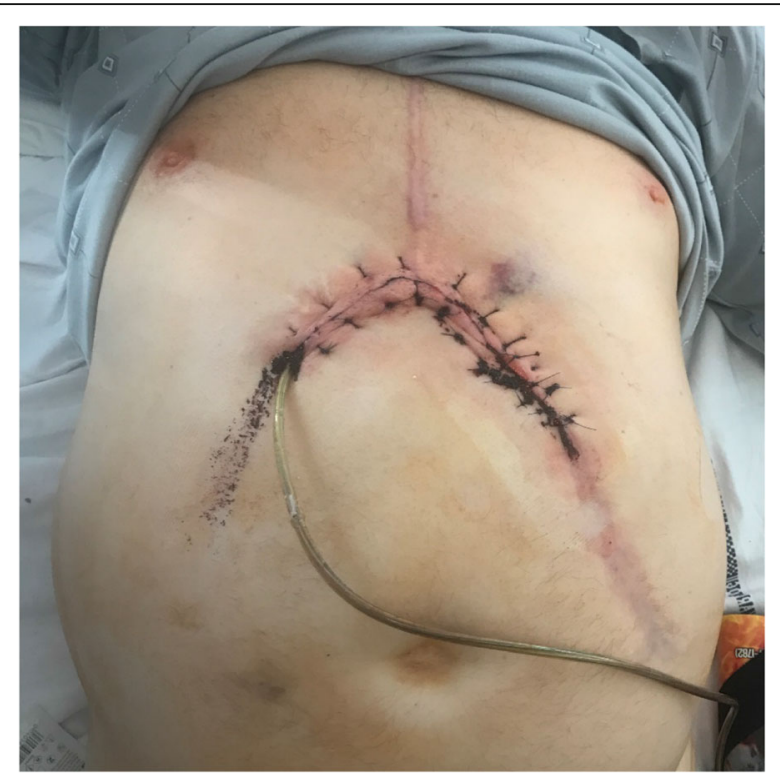

Fig. 1 The postoperative view after driveline reposition then sutured (Fig. 1). Prolonged suppressive antibiotic therapy was used.

In cases of very resistant infections, patients were placed on a list for urgent heart transplantation as last treatment resort.

\section{Statistical methods}

Driveline infection risk factors were described using odds ratios (OR) with respective 95\% confidence intervals (CI). Because of sample size we decided to perform only univariate analyses. Time of infection freedom and time to transplantation or death were described using Kaplan-Meier estimates. Log-rank test was performed to compare patient groups. All analyses were conducted using R 4.0.2 statistical software (R Core Team (2020). $\mathrm{R}$ : A language and environment for statistical computing. R Foundation for Statistical Computing, Vienna, Austria. https://www.R-project.org/).

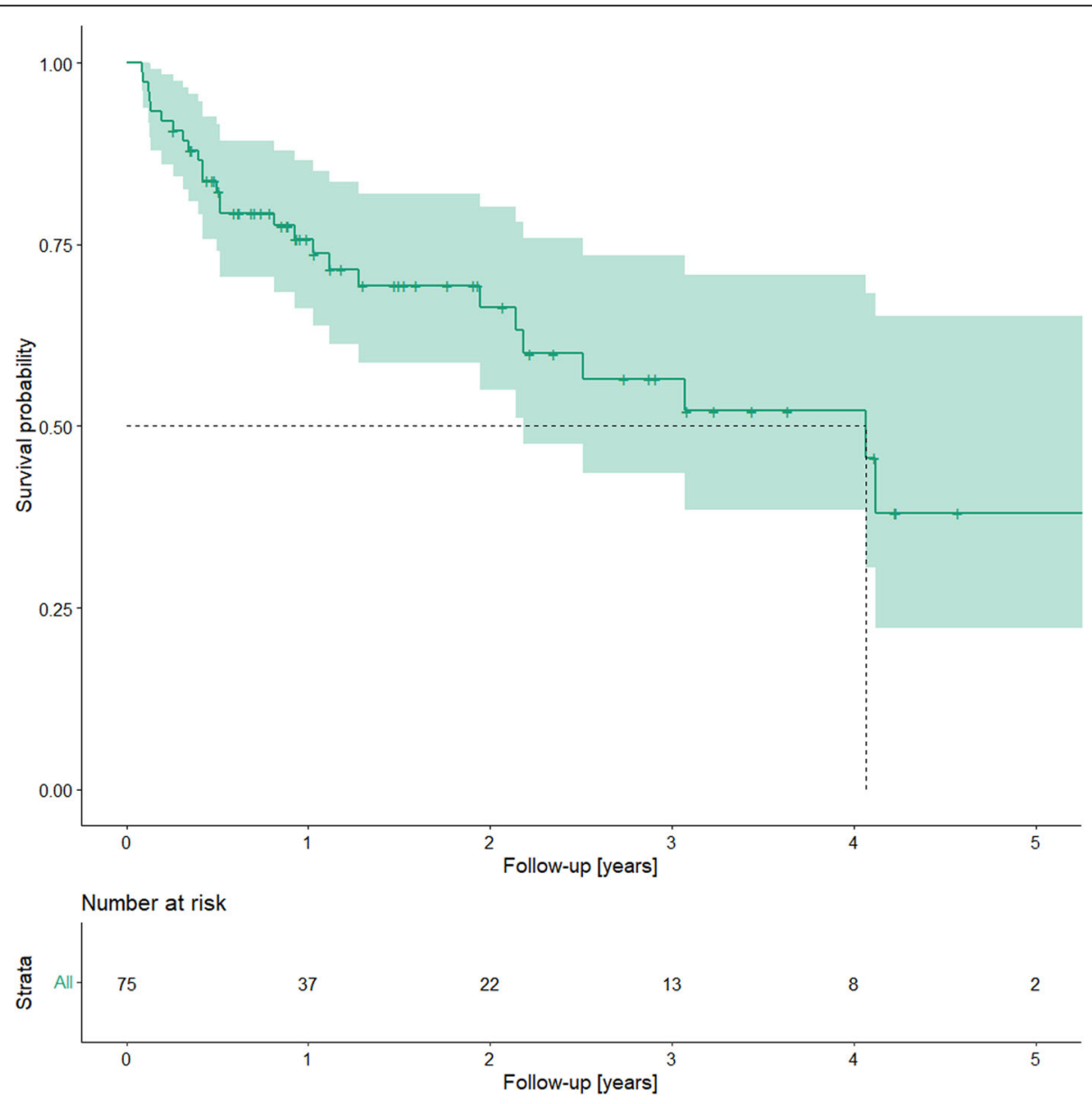

Fig. 2 A Kaplan-Meier plot of infection freedom after cf-LVAD 
Table 1 Risk factors for driveline infection

\begin{tabular}{llll}
\hline $\begin{array}{l}\text { Risk factors present at driveline infection } \\
\text { diagnosis }\end{array}$ & \multicolumn{2}{l}{ Number (\%) of patients with or without driveline infection } & OR (95\% Cl, p) \\
\cline { 2 - 3 } & Infection & No Infection & $0.50(0.18-1.34, p=0.179)$ \\
\hline Obesity & $8(25.8)$ & $23(74.2)$ & $1.05(0.40-2.74, p=0.917)$ \\
Diabetes mellitus & $12(35.3)$ & $22(64.7)$ & $1.80(0.52-6.12, p=0.342)$ \\
Age $<45$ years & $6(46.2)$ & $7(53.8)$ & $0.30(0.10-0.82, p=0.022)$ \\
ICU stay $>$ 2 weeks & $7(20.6)$ & $27(79.4)$ & $0.37(0.05-1.59, p=0.228)$ \\
History of previous mechanical circulatory support & $2(18.2)$ & $9(81.8)$ & $0.60(0.22-1.58, p=0.306)$ \\
Chronic kidney disease & $9(28.1)$ & $23(71.9)$ &
\end{tabular}

$\mathrm{Cl}$ confidence interval, $O R$ univariate odds ratio

\section{Results}

\section{Patients and data}

During the study period, 75 patients including 71 males; mean age, $54( \pm 12.9$; range $12-68.6)$ years, were treated after cf-LVAD implantation (HeartWare, $n=34,45.3 \%$; HeartMate II, $n=5$, 6.7\%; HeartMate III, $n=36,48 \%$ ). Twenty-six (34.7\%) developed a driveline infection (HeartWare, $n=13,50 \%$; HeartMate III, $n=11,42.3 \%$;
HeartMate II, $n=2,7.7 \%$ ). The median follow-up time was 2.13 years. The mean time from implantation to infection diagnosis was 463( \pm 399$)$ days (range, 35-1400 days). A Kaplan-Meier plot of infection freedom is shown in Fig. 2.

The potential risk factors for driveline infection were analyzed in Table 1. An ICU stay longer than 2 weeks was the only significant protective factor against

Table 2 Detected pathogens and antibiotics used in particular patients

\begin{tabular}{|c|c|c|c|c|c|c|}
\hline Patient & Pathogen & Antibiotic 1 & Antibiotic 2 & Antibiotic 3 & Antibiotic 4 & Antibiotic 5 \\
\hline 1 & MSSA & Clindamycinum & Cloxacillinum & - & - & - \\
\hline 2 & MSSA & Cloxacillinum & - & - & - & - \\
\hline 3 & MSSA & Ciprofloxacinum & Cefuroxime & - & - & - \\
\hline 4 & MSSA & Cloxacillinum & - & - & - & - \\
\hline 5 & P. mirabilis & Ceftriaxone & - & - & - & - \\
\hline 6 & S. agalactiae & Cefadrioxil & - & - & - & - \\
\hline 7 & MSSA & Cloxacillinum & Cefuroxime & - & - & - \\
\hline 8 & K. pneumoniae & Piperacillin + Tazobactam & Cefepime & - & - & - \\
\hline 9 & MSSA & Vancomycin & Clindamycin & - & - & - \\
\hline 10 & MRSA & Linezolid & - & - & - & - \\
\hline 11 & MSSA & Ceftazidime & Cloxacillinum & - & - & - \\
\hline 12 & S. epidermidis & Ciprofloxacinum & Vancomycin & Cloxacillinum & Rifampicin & Imipenem +Cilastatin \\
\hline 13 & K. pneumoniae & Cefepime & - & - & - & - \\
\hline 14 & UNKNOWN & UNKNOWN & - & - & - & - \\
\hline 15 & MRSA & Vancomycin & - & - & - & - \\
\hline 16 & UNKNOWN & UNKNOWN & - & - & - & - \\
\hline 17 & MSSA & Cloxacillinum & - & - & - & - \\
\hline 18 & MSSA & Cloxacillinum & Vancomycin & - & - & - \\
\hline 19 & S. pyogenes & Cefuroxime & - & - & - & - \\
\hline 20 & MSSA & Ciprofloxacinum & - & - & - & - \\
\hline 21 & MSSA & Cloxacillinum & - & - & - & - \\
\hline 22 & P. aeruginosa & Meropenem & Linezolid & Ampicillin & - & - \\
\hline 23 & MSSA & Vancomycin & Meropenem & Cloxacillinum & - & - \\
\hline 24 & P. aeruginosa & Piperacillin + Tazobactam & - & - & - & - \\
\hline 25 & MRSA/P. aeruginosa & Linezolid & Ceftazidime & - & - & - \\
\hline 26 & P. aeruginosa & Meropenem & - & - & - & - \\
\hline
\end{tabular}


driveline infection. The most common pathogen was Staphylococcus aureus $(n=15,60 \%)$. Cloxacillinum was the most frequently used antibiotic $(n=10,31.3 \%)$. The majority of patients received more than one antibacterial agent. The particular pathogens and antibiotics used in each patient are listed in Table 2 .

\section{Treatment strategy}

All patients were initially treated with antibiotics. The majority (19 patients, $73.1 \%$ ) were finally treated with surgical reposition (reposition group), and seven patients (26.9\%) were treated with antibiotics only (antibiotics group). In the reposition group, the mean time from diagnosis to surgical revision was $87( \pm 136)$ days (range, 6-555 days). Thirteen patients in the reposition group were additionally treated with vacuum dressing. Followup time after infection treatment was 569( \pm 506$)$ days (range, 32-2093 days). Among seven patients with infections managed with antibiotics alone, one patient (14.3\%) developed a reinfection. Of the 19 patients treated with surgical reposition, eight (42.1\%) developed a reinfection. Reinfection rates in the antibiotic and reposition groups are shown in Table 3. The reinfection freedom rate is shown in Fig. 3.

One death due to recurrent driveline infection occurred (Fig. 4). Eight patients (30.7\%) were treated with heart transplantation. Thirty-day mortality after urgent heart transplantation was $25 \%$. The overall mortality for driveline infection was $11.5 \%$.

\section{Discussion}

We investigated the risk factors and results of medical and surgical treatment for driveline infections in cfLVAD patients. Driveline infection was highly prevalent in cf-LVAD patients. We used a multi-modal strategy for driveline infection treatment. The first-line therapy was based on antibiotics, with a $27 \%$ primary success rate. The second step was surgical reposition, with a $57.9 \%$ primary success rate. Finally, heart transplantation was performed in $30.8 \%$ of patients for resistant infections. The infection-related mortality rate was moderate (11.5\%). This is a retrospective observational study; therefore, routines and decisions cannot be compared and may vary between subjects.

Table 3 Reinfection rates in the antibiotic and surgical reposition groups

\begin{tabular}{lcrrrrr}
\hline & & $\mathbf{n}$ & \multicolumn{2}{l}{ Reinfection } \\
\cline { 5 - 8 } & & & No & \multicolumn{3}{l}{ Yes } \\
\hline Reposition & No & 7 & 6 & $85.7 \%$ & 1 & $14.3 \%$ \\
& Yes & 19 & 11 & $57.9 \%$ & 8 & $42.1 \%$ \\
\hline$P=0.36$ (Fischer's test) & & & & &
\end{tabular}

In our series, the incidence of driveline infections was $34.7 \%$, which is similar to other reports [8]. In our center, we use accurate, daily monitoring of patients using our own telemonitoring application and regular dressing changing. This may result in a prolonged time from implantation to the development of infection, which was longer than a year in our group. In comparison, the median time from cf-LVAD implantation to the first infection event was 291 days in the MOMENTUM trial cohort [4].

Although preventing driveline infection is important, an international standard for the prevention of driveline infection after the perioperative period has not yet been defined, and many centers apply their own protocol for driveline exit site care. However, in March 2019, cfLVAD coordinators and cardiac surgeons from Germany and Austria prepared a 10-step procedure for driveline care. An advanced wound staging approach was defined with recommended actions for the prevention, early detection, and stage-related management of driveline infections [12].

Another proposed preventive double tunnel driveline technique includes placement of the driveline in the sheath of the rectus muscle in the umbilical direction and then subcutaneously to the left upper quadrant. This technique leads to significantly lowered infection rates. Indeed, 5 years after cf-LVAD implantation, the infection rate of patients operated by a double tunneling technique was $30 \%$, compared to $61 \%$ after the conventional technique [13].

As the most common complication, driveline infection remains one of the most limiting factors in cf-LVAD therapy. Recurrent and prolonged hospitalizations significantly affect the patients' quality of life. Several risk factors for the infective process have been described, most commonly, obesity [14] and younger age [15]. Particularly, younger age is associated with higher physical activity, which leads to more driveline irritation and tension. Another described issue is the velour coating on the exit site of the driveline [16]. For this reason, we performed an excessive debridement of the velour coating during the reposition surgery. This process should be performed very carefully to avoid intraoperative driveline damage. Moreover, a prolonged stay in the ICU cannot be considered a protective factor against infection in clinical practice, although we found it was statistically significantly associated with reduced infection in our analysis. The only explanation for this relationship may be the lower mobility of patients in the intensive care unit. This condition can reduce the irritation of the driveline. However, extending the stay in the intensive care unit may not be determined by the desire to avoid driveline infection. Interestingly, obesity was not recognized as a risk factor for developing driveline infection. 


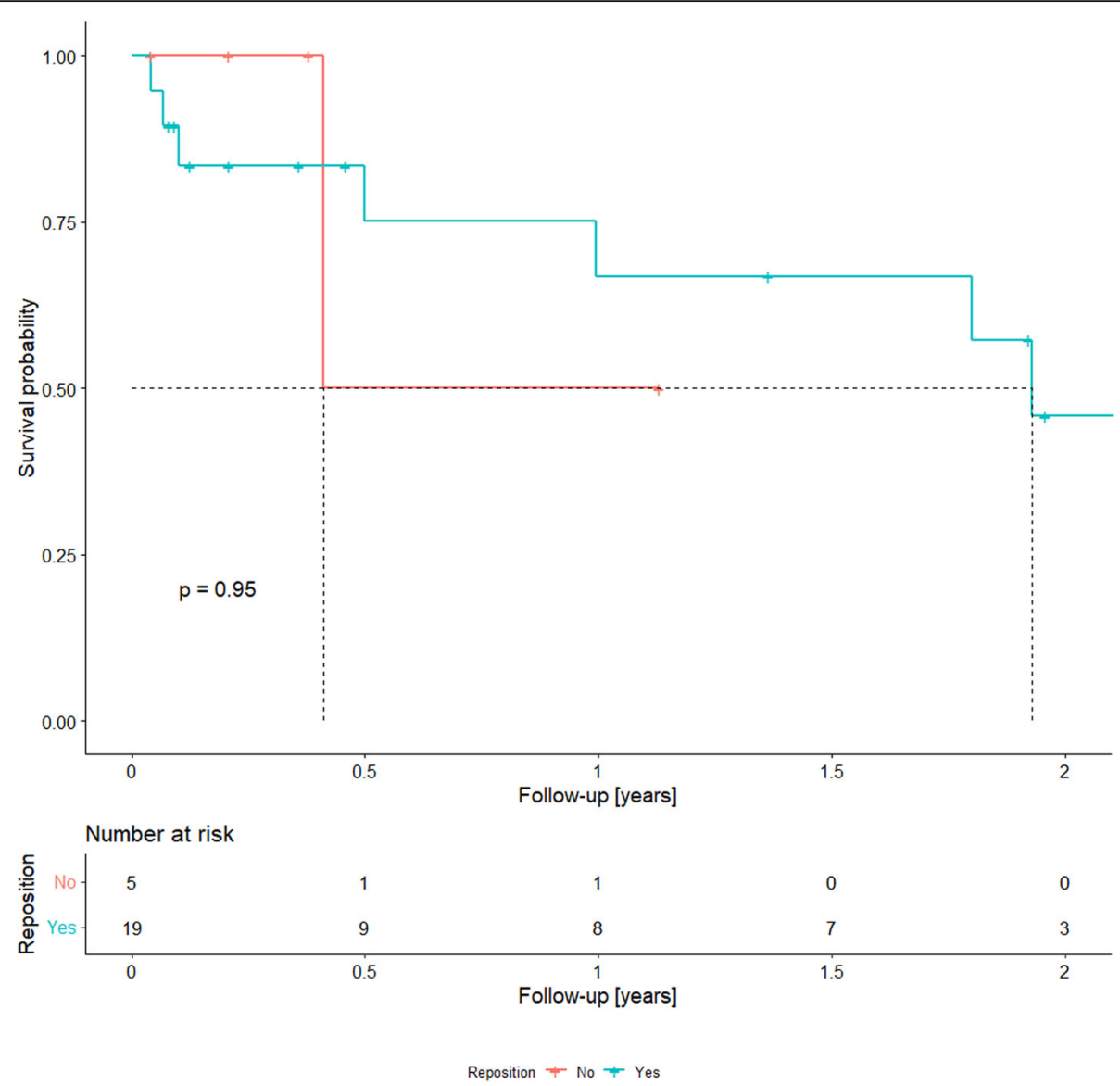

Fig. 3 A Kaplan-Meier plot of reinfection freedom after driveline infection depending on treatment type

This confirms the significant role of irritation and increased mobility in the development of driveline infections.

The low number of patients cured with antibiotics alone in our center indicates the ineffectiveness of this method. Moreover, although an aggressive surgical strategy of driveline debridement and reposition of the driveline exit site is a reasonable treatment option, the results of surgical reposition are limited. Our preliminary results of 45 patients in the observation period from 2014 to 2019 suggested surgical reposition were promising, with only $20 \%$ of patients treated surgically who developed reinfection during the follow-up time of $425( \pm 487)$ days, range, 38-1644 days. However, after a follow-up of more than 2 years, the reinfection rate has increased to almost 60\% [17].

Being a growing cf-LVAD center, we were forced to perform heart transplantation in very resistant infections. Urgent transplantation was characterized by significant early mortality. We have not yet used the relocation technique with the omentum. Although it seems to be a feasible and effective procedure in selected cases, the reported risk for perioperative bleeding is significant [18]. Interestingly, in the study performed by Radcliffe et al., chronic, prolonged antibiotic therapy (mean 486 days; range, 48-2287 days) led to successful outcomes in $50 \%$ of patients [11]. Therefore, significantly prolonged antibiotic therapy may be required in cfLVAD patients.

Although the surgical driveline reposition is a viable treatment option, our strategy has moved towards antibiotics administration over an extended period of time as a first-line treatment. We had hoped that the surgical reposition technique was so effective that it would avoid heart transplantation due to infection; however, we were still forced to perform heart transplantation in a case of resistant infection as the last treatment resort. The management of a particular cf-LVAD center should be subject to continuous analysis of the results to optimize the treatment strategy.

Finally, competitively to heart transplantation with a limited donor pool, some innovative strategies should be considered. For example, cold atmospheric plasma application is a new tool for the treatment of superficial driveline infections. Cold atmospheric plasma creates reactive oxygen and nitrogen species that can inactivate 


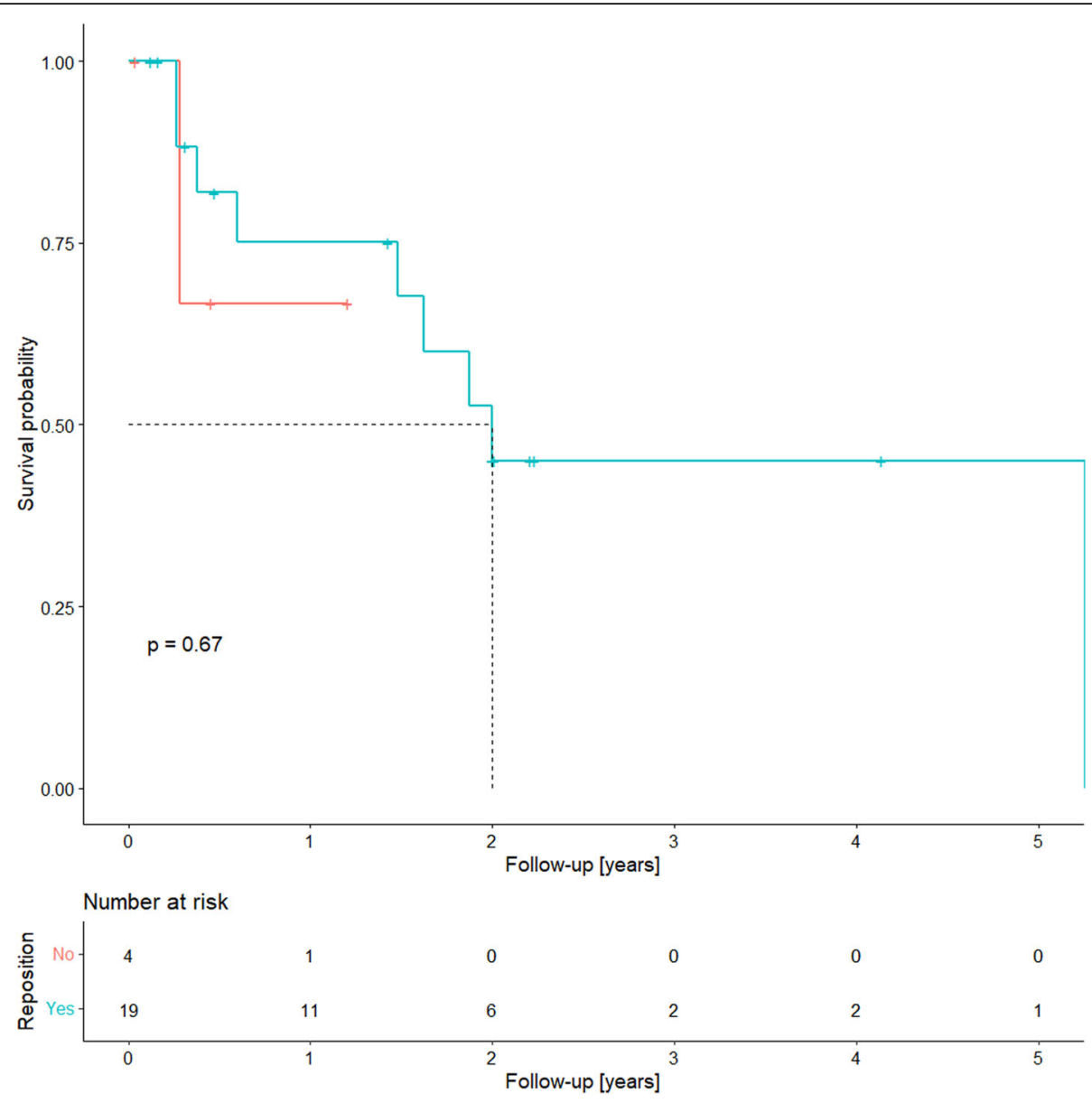

Fig. 4 A Kaplan-Meier plot of freedom from transplantation or death after driveline infection depending on treatment type

microorganisms, including multi-resistant strains. Indeed, Hilker et al. reported a case of a patient with HeartWare cf-LVAD, in which the local infection was completely healed after 12 applications of cold plasma [19]. However, this promising approach requires further confirmation in a larger cohort of patients.

\section{Conclusions}

Although the prevalence of driveline infection was high in our center, and treatment did not efficiently avoid reinfection, it was associated with moderate mortality. Only a minority of infected patients were cured with antibiotics alone, and the results of surgical driveline reposition were limited. For those reasons, heart transplantation is becoming the ultimate therapy in a growing number of patients. Nonetheless, the management of a particular cf-LVAD center should be subject to continuous analysis of the results to optimize the multi-modal treatment strategy. In the future, competitively to heart transplantation with a limited donor pool, alternative approaches should be developed.

\section{Limitations}

Retrospective nature of the study, limitation to a single care center.

\section{Abbreviations}

cf-LVAD: Continuous-flow left ventricular assist devices; BMI: Body mass index; ICU: Intensive care unit; MCS: Mechanical circulatory support; GFR: Glomerular filtration rate

\section{Supplementary Information}

The online version contains supplementary material available at https://doi. org/10.1186/s13019-021-01589-6.

Additional file 1. Pathogens and detailed antibiotic therapy.

\section{Acknowledgements}

Dr. Dziodzio is participant in the BlH-Charité Clinician Scientist Program funded by the Charité -Universitätsmedizin Berlin and the Berlin Institute of Health.

\section{Authors' contributions}

AJ- acquisition, analysis and interpretation of data, writing, final approval, checking the accuracy and integrity of the work. MSm- acquisition, analysis and interpretation of data, writing, final approval, checking the accuracy and integrity of the work. PK- interpretation of data, writing, final approval, checking the integrity of the work. JS- interpretation of data, writing, final 
approval, checking the integrity of the work. KK- interpretation of data, fina approval, checking the integrity of the work. JZK- interpretation of data, writing, final approval, checking the integrity of the work. MSt- interpretation of data, writing, final approval, checking the integrity of the work. MKconcept, acquisition, analysis and interpretation of data, writing, final approval, checking the accuracy and integrity of the work. TD- concept, acquisition, analysis and interpretation of data, writing, final approval, checking the accuracy and integrity of the work.

\section{Funding}

Open Access funding enabled and organized by Projekt DEAL.

\section{Availability of data and materials}

The datasets used and/or analysed during the current study are available from the corresponding author on reasonable request.

\section{Declarations}

\section{Ethics approval and consent to participate}

Not applicable.

\section{Consent for publication}

Not applicable.

\section{Competing interests}

Maciej Sterliński received fees from Abbott, Biotronik, Boston Scientific, Medtronic, Zoll.

Other authors declare that they have no competing interests.

\section{Author details}

'Department of Cardiac Surgery and Transplantation, The Cardinal Stefan Wyszyński National Institute of Cardiology, ul. Alpejska 42, 04-628 Warsaw, Poland. ${ }^{2}$ Medical University of Warsaw, Warsaw, Poland. ${ }^{3} 1$ st Department of Arrhythmia, The Cardinal Stefan Wyszyński National Institute of Cardiology, Warsaw, Poland. ${ }^{4}$ Department of Surgery, Campus Charité Mitte and Campus Virchow-Klinikum Charité -Universitätsmedizin Berlin, corporate member of Freie Universität Berlin, Humboldt-Universität zu Berlin, and Berlin Institute of Health, Augustenburger Platz 1, 13353 Berlin, Germany.

Received: 22 May 2021 Accepted: 17 July 2021

Published online: 03 August 2021

\section{References}

1. Biełka A, Kalinowski M, Hawranek M, Małyszek-Tumidajewicz J, Pacholewicz J, Kowalczuk-Wieteska A, et al. Mechanical circulatory support restores eligibility for heart transplant in patients with significant pulmonary hypertension. Kardiol Pol. 2020;78(10):1008-14. https://doi.org/10.33963/KP.1 5518 Epub 2020 Jul 17. PMID: 32692025.

2. Loyaga-Rendon RY, Jani M, Fermin D, McDermott JK, Vancamp D, Lee S. Prevention and treatment of thrombotic and hemorrhagic complications in patients supported by continuous-flow left ventricular assist devices. Curr Heart Fail Rep. 2017;14(6):465-77. https://doi.org/10.1007/s11897-017-0367-3.

3. O'Horo JC, Abu Saleh OM, Stulak JM, Wilhelm MP, Baddour LM, Rizwan SM. Left Ventricular Assist Device Infections: A Systematic Review. ASAIO J. 2018; 64(3):287-94.

4. Patel CB, Blue L, Cagliostro B, Bailey SH, Entwistle JW, John R, et al. Left ventricular assist systems and infection-related outcomes: a comprehensive analysis of the MOMENTUM 3 trial. J Heart Lung Transplant. 2020;39(8):77481. https://doi.org/10.1016/..healun.2020.03.002.

5. Kirklin JK, Pagani FD, Kormos RL, Stevenson LW, Blume ED, Myers SL, et al. Eighth annual INTERMACS report: special focus on framing the impact of adverse events. J Heart Lung Transplant. 2017;36(10):1080-6. https://doi. org/10.1016/j.healun.2017.07.005.

6. Leuck AM. Left ventricular assist device driveline infections: recent advances and future goals. J Thorac Dis. 2015;7(12):2151-7. https://doi.org/10.3978/j. issn.2072-1439.2015.11.06.

7. Balsam LB, Jacoby A, Louie E, Levine JP. Long-Term Success With Driveline Exit Site Relocation for Deep Driveline Infection in Left Ventricular Assist Device Patients. Innovations (Phila). 2017;12(6):440-5.
8. Rahal A, Ruch $\mathrm{Y}$, Meyer $\mathrm{N}$, et al. Left ventricular assist device-associated infections: incidence and risk factors. J Thorac Dis. 2020;12(5):2654-62. https://doi.org/10.21037/jtd.2020.03.26.

9. Putnik S, Terzić D, Nestorović E, Karan R, Dobri M, Andrijasević $V$, et al. Prevention, treatment and outcomes of left ventricular assist device driveline infections. A single center experience. Ann Ital Chir. 2020;91:8-15.

10. Zinoviev R, Lippincott CK, Keller SC, Gilotra NA. In Full Flow: Left Ventricular Assist Device Infections in the Modern Era. Open Forum Infect Dis. 2020; 7(5):ofaa124. Published 2020 Apr 17. https://doi.org/10.1093/ofid/ofaa124.

11. Radcliffe C, Doilicho N, Niu YS, Grant M. Efficacy and safety of chronic antimicrobial suppression therapy for left ventricular assist device driveline infections: a single-center descriptive experience. Transpl Infect Dis. 2020; 22(5):e13379. https://doi.org/10.1111/tid.13379.

12. Bernhardt AM, Schlöglhofer T, Lauenroth V, Mueller F, Mueller M, Schoede $A$, et al. Prevention and early treatment of driveline infections in ventricular assist device patients - the DESTINE staging proposal and the first standard of care protocol. J Crit Care. 2020;56:106-12. https://doi.org/10.1016/j.jcrc.2 019.12.014.

13. Wert L, Hanke JS, Dogan G, Ricklefs M, Fleißner F, Chatterjee A, et al. Reduction of driveline infections through doubled driveline tunneling of left ventricular assist devices-5-year follow-up. J Thorac Dis. 2018;10(Suppl 15): S1703-10. https://doi.org/10.21037/jtd.2018.03.127.

14. Martin BJ, Luc JGY, Maruyama M, MacArthur R, Bates AR, Buchholz H, et al. Driveline Site Is Not a Predictor of Infection After Ventricular Assist Device Implantation. ASAIO J. 2018;64(5):616-22.

15. Rubinfeld G, Levine JP, Reyentovich A, DeAnda A, Balsam LB. Management of Rapidly Ascending Driveline Tunnel Infection. J Card Surg. 2015;30(11): 853-5. https://doi.org/10.1111/jocs.12655.

16. Pavlovic NV, Randell T, Madeira T, Hsu S, Zinoviev R, Abshire M. Risk of left ventricular assist device driveline infection: A systematic literature review. Heart Lung. 2019:48(2):90-104.

17. Juraszek A, Kołsut P, Szymański J, Kuriata J, Sobieszczańska-Małek M, Zieliński T, et al. Clinical Strategies and Results of Medical Treatment and Surgical Reposition Technique for Driveline Infections in Patients with ContinuousFlow Left Ventricular Assist Devices. J Heart Lung Transplant. 2020;39(4): S489.

18. Pieri M, Scandroglio AM, Müller M, Pergantis $P$, Kretzschmar A, Kaufmann F, et al. Surgical management of driveline infections in patients with left ventricular assist devices. J Card Surg. 2016;31(12):765-71. https://doi.org/1 $0.1111 /$ jocs. 12860

19. Hilker L, von Woedtke T, Weltmann KD, Wollert HG. Cold atmospheric plasma: a new tool for the treatment of superficial driveline infections. Eur J Cardiothorac Surg. 2017;51(1):186-7. https://doi.org/10.1093/ejcts/ezw212.

\section{Publisher's Note}

Springer Nature remains neutral with regard to jurisdictional claims in published maps and institutional affiliations.

\section{Ready to submit your research? Choose BMC and benefit from:}

- fast, convenient online submission

- thorough peer review by experienced researchers in your field

- rapid publication on acceptance

- support for research data, including large and complex data types

- gold Open Access which fosters wider collaboration and increased citations

- maximum visibility for your research: over $100 \mathrm{M}$ website views per year

At BMC, research is always in progress.

Learn more biomedcentral.com/submissions 